\title{
Correction to: National prevalence rate of hepatitis B and C in Pakistan and its risk factors
}

\author{
Shahid Mehmood ${ }^{1} \cdot$ Hassan Raza ${ }^{1} \cdot$ Farhan Abid $^{1} \cdot$ Nouman Saeed $^{1} \cdot$ Hafiz Muzzammel Rehman $^{2} \cdot$ Safdar Javed $^{3} \cdot$ \\ Muhammad Saleem Khan ${ }^{4}$ (D)
}

Published online: 23 July 2019

(C) Springer-Verlag GmbH Germany, part of Springer Nature 2019

\section{Correction to: Journal of Public Health: From Theory to Practice https://doi.org/10.1007/s10389-019-01081-5}

During typesetting of the article, one of alphabet was missed in author name Hafiz Muzzammel Rehman and it became "Rehan".

The original article has been corrected.

Publisher's note Springer Nature remains neutral with regard to jurisdictional claims in published maps and institutional affiliations.

The online version of the original article can be found at https://doi.org/ 10.1007/s10389-019-01081-5

\section{Muhammad Saleem Khan} samiikhan@yahoo.com

1 Department of Zoology, University of the Punjab, Lahore, Pakistan

2 Institute of Biochemistry and Biotechnology, University of the Punjab Lahore, Lahore, Pakistan

3 Institute of Chemical Sciences, Bahauddin Zakariya University, Multan, Pakistan

4 Department of Zoology, Government College University, Faisalabad, Pakistan 